\title{
Prophylactic appendectomy in the heart?
}

\author{
Joon Bum Kim, MD, PhD
}

\footnotetext{
From the Department of Thoracic and Cardiovascular Surgery, Asan Medical Center, University of Ulsan College of Medicine, Seoul, Republic of Korea.

Disclosures: Author has nothing to disclose with regard to commercial support.

Received for publication March 27, 2018; accepted for publication March 29, 2018; available ahead of print April $25,2018$.

Address for reprints: Joon Bum Kim, MD, PhD, Department of Thoracic and Cardiovascular Surgery, Asan Medical Center, University of Ulsan College of Medicine, 388-1 Pungnap-dong, Songpa-gu, Seoul 138-736, Republic of Korea (E-mail: jbkim1975@amc.seoul.kr).

J Thorac Cardiovasc Surg 2018;156:1083-4

$0022-5223 / \$ 36.00$

Copyright (C) 2018 by The American Association for Thoracic Surgery

https://doi.org/10.1016/j.jtcvs.2018.03.141
}

Incidental appendectomy during other abdominal surgeries has been a relatively common practice supported by the high lifetime risk of appendicitis of $6 \%$ to $9 \%$ and the low procedural risk. ${ }^{1,2}$ The appendage in the heart may matter more. Although the left atrial appendage (LAA) is known to have booster and some endocrine functions, it is also the most common thromboembolic source once atrial fibrillation (AF) has occurred. On average, AF seems to occur more frequently than appendicitis during one's lifetime, with the prevalence of AF reaching around 10\% around the age of 70 years and climbing even higher afterward. ${ }^{3}$ Because its associated risks of death and stroke, health burdens related to AF are becoming more and more important in aging societies. Of note, the LAA has been one of the most important targets of AF therapies. With the introduction of new devices, LAA closure procedures have become more sophisticated and less invasive, but they are still time-consuming and costly.

Opening the chest to correct structural heart diseases may provide the best opportunity to get rid of this potential nidus in the easiest way - a chance that may be given only once in a patient's lifetime. Concomitant surgical LAA closure is not free of cost, however; many surgeons may recall painful memories of troublesome bleeding and sometimes lifethreatening coronary injury associated with LAA closure. In this view, the question of risk versus benefit of concomitant LAA closure during cardiac surgery is in need of adequate answers.

To address this controversial issue, Ando and colleagues ${ }^{4}$ present in this issue of the Journal a meta-analysis that included 3897 patients in 8 published articles. For fair comparisons, Ando and colleagues ${ }^{4}$ retrieved only articles that had randomized trials $(\mathrm{n}=3)$ or adjusted outcomes $(n=5)$. This is the unique strength of the study compared with previous articles.

LAA closure during cardiac surgery did not seem to increase procedural risks, but it was significantly associated with lower 30-day risks of mortality (odds ratio, 0.384; $95 \%$ confidence interval, $0.233-0.631$ ) and stroke (odds ratio,

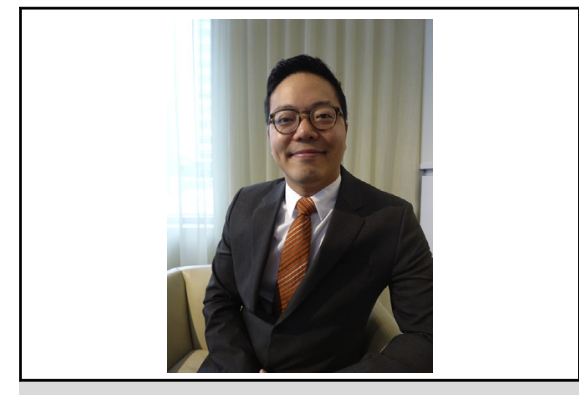

Joon Bum Kim, MD, PhD

Central Message

Will left atrial appendage closure benefit even those without atrial fibrillation undergoing coronary surgery? Is it obligatory for those undergoing concomitant atrial fibrillation ablation surgery?

See Article page 1071.

$0.622 ; 95 \%$ confidence interval, $0.388-0.998)$, especially in those with greater AF prevalence and those undergoing valve surgery. These lower risks are likely to be associated with LAA closure in patients with preexisting AF persisting postoperatively (regardless of ablation therapy), but postoperative new-onset AF may also have interacted. In contrast, for subgroups of patients that were predominantly composed of those undergoing coronary surgery or those without AF, the benefits of LAA closure seemed unclear.

Perhaps it is long-term comparative outcomes that are of more interest; it is regrettable that the study could not investigate on the late outcomes because hazard ratios for these could not be summarized for many technical reasons. Despite rigorous efforts to balance the baseline profiles, potential residual selection bias is also not a negligible issue, because the 3 randomized trials included in the study only accounted for $4.4 \%$ of the entire cohort (171/2464), and therefore the study outcomes relied heavily on observational studies. In addition, results on mortality were evaluated only by 3 observational studies. Other limitations of the study include a lack of sufficient data regarding the methods of LAA closure, AF status, and details of AF ablation procedure. Of note, 1 propensity score-matching study on concomitant mitral valve and AF ablation surgery did not show any significant differences in the rates of mortality and stroke with or without LAA closure.

Despite these limitations, the article of Ando and colleagues ${ }^{4}$ surely has value in offering insights into the impact 
of LAA closure in cardiac surgery and bringing up further important questions to be answered. Will LAA closure benefit even patients without AF undergoing coronary surgery? Is it obligatory for patients undergoing concomitant AF ablation surgery? We can expect further troubleshooter articles to address these issues.

\section{References}

1. Strom PR, Turkleson ML, Stone HH. Safety of incidental appendectomy. Am J Surg. 1983;145:819-22.
2. Addiss DG, Shaffer N, Fowler BS, Tauxe RV. The epidemiology of appendicitis and appendectomy in the United States. Am J Epidemiol. 1990;132:910-25.

3. Friberg L, Bergfeldt L. Atrial fibrillation prevalence revisited. J Intern Med. 2013; 274:461-8.

4. Ando M, Funamoto M, Cameron DE, Sundt TM III. Concomitant surgical closure of left atrial appendage: a systematic review and meta-analysis. J Thorac Cardiovasc Surg. 2018;156:1071-80.e2.

5. Tsai YC, Phan K, Munkholm-Larsen S, Tian DH, La Meir M, Yan TD. Surgical left atrial appendage occlusion during cardiac surgery for patients with atrial fibrillation: a meta-analysis. Eur J Cardiothorac Surg. 2015;47:847-54.

6. Lee CH, Kim JB, Jung SH, Choo SJ, Chung CH, Lee JW. Left atrial appendage resection versus preservation during the surgical ablation of atrial fibrillation. Ann Thorac Surg. 2014;97:124-32. 